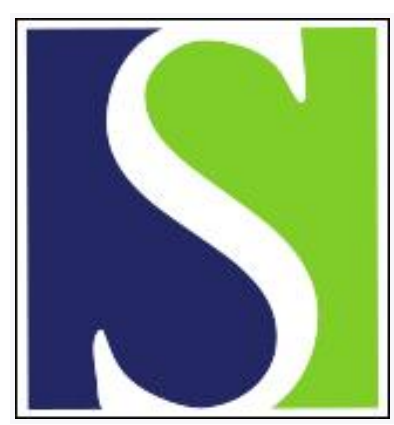

Scand J Work Environ Health 2015;41(2):216-217

https://doi.org/10.5271/sjweh.3473

Published online: 11 Dec 2014, Issue date: 01 Mar 2015

Re: Madsen et al. "Unnecessary work tasks and mental health: a prospective analysis of Danish human service workers" by Durand-Moreau Q, Loddé B, Dewitte J-D

Affiliation: Occupational and Environmental Diseases Center, University Hospital of Brest, 5 Avenue Foch, 29609 Brest, France. quentin.durand-moreau@chu-brest.fr

Refers to the following text of the Journal: 2014;40(6):631-638

The following article refers to this text: 2015;41(2):218

Key terms: letter to the editor; mental health; unnecessary work task

This article in PubMed: www.ncbi.nlm.nih.gov/pubmed/25501916

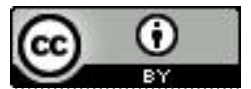




\section{Re: Madsen et al. "Unnecessary work tasks and mental health: a prospective analysis of Danish human service workers"}

Madsen et al (1) recently published a secondary analysis on data provided by the Project on Burnout, Motivation and Job Satisfaction (PUMA). The aim of their study, published in the Scandinavian Journal of Work, Environment \& Health was to examine the associations between unnecessary work tasks and a decreased level of mental health. Though the topic was quite novel, reading this work proved disturbing and raised issues.

Based on the results of this study, the authors stated that there is an association between unnecessary work tasks (assessed by a single question) and a decreased level of mental health, idem [assessed by the Mental Health Inventory (MHI-5)], in the specific population included in this PUMA survey.

The authors point out a limitation of the study, namely that unnecessary work tasks were evaluated using one single question: "Do you sometimes have to do things in your job which appear to be unnecessary?". Semmer defines unnecessary work task as "tasks that should not be carried out at all because they do not make sense or because they could have been avoided, or could be carried out with less effort if things were organized more efficiently" (2). De facto, qualifying what an unnecessary task is requires stating or explaining whether the task makes sense. Making sense or not is not an objective notion. It is very difficult for either a manager or an employee to say if a task is necessary or not. Most important is that it makes sense from the worker's point of view. Making sense and being necessary are not synonyms. Some tasks do not make sense but are economically necessary (eg, when, as physicians, we are reporting our activity using ICD-10 on computers instead of being at patients' bedsides or reading this journal). Thus, there is a wide gap between Semmer's definition and the question used by the authors to evaluate his concept. A secondary analysis based on a single question is not adequate to evaluate unnecessary tasks.

Nowadays, the general trend is to reduce the size of questionnaires because they are too long and cannot be used in a routine practice. But an analysis performed on a single question is quite risky: in psychometrics, redundancy is used to confirm a measurement. We lose precision on what exactly we are testing by asking a single question.

Madsen et al's results show that among workers saying they are always or often performing unnecessary tasks, the MHI mean score was 74.00 versus 78.20 for people who never or almost never perform unnecessary tasks $(\mathrm{P}=0.0038)$. Even though it is a statistically significant result, its clinical relevance is never questioned. What is the impact of losing 4.20 points at MHI test instead of losing 20 points for instance? Statistical difference does not mean clinical relevance.

These results show a statistical association, not a causality relationship. The authors did not show that performing unnecessary tasks lowers the level of mental health. It may be the exact opposite. Maybe having poorer mental health (eg, depression, with anhedonia) may make the workers think that what they're doing is useless.

In their conclusion, Madsen et al suggest that the elimination of unnecessary work tasks may be beneficial for employees' mental health. To our mind, on the contrary, it may increase psychic suffering. If we suggest to fight unnecessary tasks in workplaces, this may encourage reduction of the margin of manoeuvre (3). The principle of removing unnecessary tasks is part of a Taylorized organization. Some tasks may seem unnecessary or bothersome, but may correspond to work periods that allow for temporary rest. Concretely, in the workplace, managers rather than the employee will be the ones to decide whether a task is useless or not. To improve well-being in the workplace, a global vision of work organization is required.

From our point of view, the conclusion drawn from this study should not be that we must eliminate unnecessary tasks, but that we should focus on what makes sense for the worker, with a global view on his work and - as usual - the aim of carrying out further studies on this subject.

\section{Conflicts of interest}

The authors declare no conflict of interest.

\section{References}

1. Madsen IEH, Tripathi M, Borritz M, Rugulies R, Unnecessary work tasks and mental health: a prospective analysis of Danish human service workers, Scand J Work Environ Health. 2014;40(6):631-8. http://dx.doi.org/10.5271/sjweh.3453. 
2. Semmer NK, Tschan F, Meier LL, Facchin S, Jacobshagen N, Illegitimate tasks and counterproductive work behavior, Appl Psychol. 2010;59:70-96. http://dx.doi.org/10.1111/j.14640597.2009.00416.x.

3. Durand MJ, Vézina N, Baril R, Loisel P, Richard MC, Ngomo $\mathrm{S}$, Margin of manoeuvre indicators in the workplace during the rehabilitation process: a qualitative analysis, J Occup Rehab 2009;19:194-202. http://dx.doi.org/10.1007/s10926-0099173-4.
Quentin Durand-Moreau, MD, ${ }^{1,2}$ Brice Loddé, MD, ${ }^{1,2}$

Jean-Dominique Dewitte, MD, PhD ${ }^{1,2}$

1 Occupational and Environmental Diseases Center, University Hospital of Brest, Brest, France.

2 European University of Brittany, University of Brest, Brest, France.

Correspondence to: Dr Quentin Durand-Moreau, Occupational and Environmental Diseases Center, University Hospital of Brest, 5 Avenue Foch, 29609 Brest, France. [E-mail: quentin.durandmoreau@chu-brest.fr] 